\begin{tabular}{|c|c|c||}
\hline Received: August 2019 & Accepted: September 2019 & Published: October 2019 \\
\hline \hline \multicolumn{3}{|c|}{ Article DOI: http://dx.doi.org/10.24903/sj.v4i2.331 } \\
\hline
\end{tabular}

\title{
Weblog as an Appropriate Online Medium in Teaching Writing
}

\author{
Sandi Pradana \\ Universitas Negeri Yogyakarta \\ Sandi.pradana@student.uny.ac.id \\ Ashadi \\ Universitas Negeri Yogyakarta \\ ashadi@uny.ac.id
}

\begin{abstract}
This research aims to develop weblog as media in teaching writing of senior high school students. The procedure of developing media consisted of analyzing learners, stating objectives, selecting media, utilizing media, requiring learner participation, evaluating and revising. The product was examined by the media expert. After conducting the first test, the second test was conducted by English teachers and students. The subjects of this research were the eleventh-grade students of SMAN 1 Piyungan, Bantul, Yogyakarta. The subject consisted of 19 students of class XI. The researcher used an interview and questionnaires as the data collecting technique. The questionnaires were distributed for needs analysis and expert validation. English teacher and students responded toward the developed weblog. The data were analyzed using descriptive statistics for the questionnaires and the qualitative analysis technique for the interview. The findings revealed that the developed weblog as online media in teaching writing is categorized "very good" by experts with the mean scores put on 3.82 . The result of the score of the tryout is 3.48 and categorized as very good. The English teacher's response towards the weblog shows the range of average mean score on 3.69 categorized "very good". Therefore, the developed weblog is very appropriate to use in the teaching and learning process of writing.
\end{abstract}

Keywords: CALL; weblog; writing; senior high school

\section{INTRODUCTION}

For teachers, teaching aids certainly amplify their effortful presentation more into influencing instructions. The use of a variety of teaching aids has successfully transformed 
most classrooms from traditional setup, where teachers do most of the talking and students are passive listeners, into participatory learning centers facilitating productive learning (Thomas, 2014).

Some kinds of media can be used in the teaching and learning process. However, every media has different effects depending on the students' needs. Hence, we should find an appropriate medium in teaching to promote students' English skills. By emphasizing the use of the media, the teaching and learning process can be done effectively and the students can earn good language skills.

In the modern era, the development of media increases rapidly. Teaching using technology in the classroom setting can assist students' learning. Technology can help the teacher achieve instructional objectives. However, it can be challenging for the teachers to select the best technology tool while not losing the essence goals for students learning. Teaching and learning by using online media is one way to get closer to ICT (Information, Communication, and technology). Teachers who make use of online media in the teaching and learning process have the opportunity for creating autonomous learning (Hietanen, Ruokonen, Ruismäki, \& Enbuska, 2016; Kramer \& Kusurkar, 2017; Leiker et al., 2016)

In the online classroom setup, teachers can decide when and how the students learn, as well as control the speed at which the students are learning. Teachers as the instructors need to be able to clarify, assist, and aid in technical problems that can occur. It will require schools to provide additional training to their teachers that may have additional cost and time (Terrill, 2000). In addition to teaching through media, new technologies that could help us teach writing in the second language (Karimkhanlooei \& Seifiniya, 2015; Kim \& Crossley, 2018). (Kim \& Crossley, 2018; Lee, 2015) also highlights that the computer can be used to teach new types of writing considering the online age today.

The researcher decided to develop online media that can be effectively used in teaching writing. It is developed by determining students' lack, wants and necessities. The researcher does hope these online media could convey various topics and a new option for teachers and students in teaching and learning writing.

Some problems can be identified. The first problem comes from students. The students have poor writing output. On the other hand, the teacher only uses printed materials such as textbooks and worksheets during the teaching and learning process. The students want to learn more about various topics in writing. 
The second comes from the use of media in teaching English at the senior high school should be optimized. Senior high school, especially SMAN 1 Piyungan has certain facilities that can be optimized as a media in the teaching and learning process. The teacher needs to introduce teaching English using new media to support students' achievement in writing class.

The other problem concerns in online media as a supporting tool in the teaching and learning process. Weblog, as one of the online media, has certain characteristics that can be used to overcome students' reluctance and teachers' weaknesses in writing classes. The teacher realizes the importance of online media in the process of teaching and learning. The teacher does not have the basic ability and spare time to design and develop online media. Furthermore, it also needs the support of the headmaster of the school to provide a training program for the teacher to be able to make use of online media in the teaching and learning process.

By conducting this research, the researcher would like 1) to identify the students' learning needs in writing English text, 2) to find out the students' target need in writing English text, 3) to figure out how the weblog was developed, and 4) to provide weblog as an appropriate medium in teaching writing class. The product of this research is a weblog, a web-based media for teaching writing. The weblog was designed for eleventh-grade students of Senior High School by using NEO-LMS v1.15.

Related to the kinds of media in teaching, weblog as teaching media is under Computer Assisted Language Learning (CALL). Computer-Assisted Language Learning (CALL) software is language-learning software that has lessons and activities developed for the specific needs of an objective group. CALL is typically aimed for second language acquisition. (Pirasteh, 2014; Stickler \& Shi, 2016) specified that nothing can compare to a teacher-learner classroom environment and CALL can be defined as the study of applications of the computer in language teaching and learning. Ideally, CALL should be used as a part of conjunction with the classroom-based curriculum in a mixed learning situation to give the most ideal learning environment.

(Başöz \& Çubukçu, 2014; Su, Tseng, Jang, \& Visceglia, 2018) clarified that this term is widely used in the area of technology and second language teaching. Given a breadth, Beatty (2013; Rafiee \& Purfallah, 2014; Zaini \& Mazdayasna, 2014) defines CALL as any process in which learners use a computer and improve their language as a result. The development is also followed by revision for the term. The computer as media in teaching and learning changes standpoints of students in using it. Furthermore, CALL encompasses issues of materials design, pedagogical theories, technologies, and models of instruction. The English teacher is easy to 
include those issues for language learning and adapt existing computer-based materials and videos.

Also, CALL shows an integrative approach whereby the CALL program does not replace the classroom content but rather is directed into the course as a learning resource. Regularly, it takes a self-study form that takes place outside the classroom hours, especially for the parallel class.

\section{METHODOLOGY}

The researcher used this model because of the integration of technology and media in this research (Smaldino, Lowther, \& Russell, 2005). The result of this research is an online weblog by emphasizing writing instructional for eleventh-grade students by using NEO Cloudbased Learning management system organized by CHYPER LEARNING.

The research was conducted in SMAN 1 Piyungan. The subjects of this research were chosen from the same grade that has similar characteristics to the real subject. The tryout subjects consisted of 19 students. In deciding tryout classes, the researcher asked for the English teacher's recommendation.

The researcher collected qualitative and quantitative. The qualitative data were collected through observation and interview. The quantitative data were collected by conducting questionnaires. The data of this research were quantitative and qualitative data. The result of the data analysis was used for revising the product which was developed.

The second data were obtained in the interview. In this step, the data were analyzed using descriptive qualitative. The interview was conducted at the beginning of the research step as the needs analysis. The interview was also recorded and reported in the written form of the interview transcript.

There are three kinds of the questionnaire used in this research to obtain different quantitative data. The first questionnaire was used to obtain data related to the learning and target needs of the students. The second questionnaire was used to collect data from expert judgments. The third questionnaires were used to collect media evaluation data from the students and English teacher. The descriptive statistic was used to analyze all the collected data from those questionnaires.

The data from all those questionnaires were measured by using a Likert scale with four points scale (strongly agree, agree, disagree, strongly disagree). The data from the first questionnaire were described in percentages. Nevertheless, the other questionnaires were interpreted into numerical values 1-4. The data were analyzed in the form of descriptive 
statistical analysis. Afterward, the categories were determined based on the criteria. Suharto (2006), proposed the quantitative data conversion as presented in quantitative data conversion.

Table 1. Quantitative Data Conversion

\begin{tabular}{lll}
\hline Scales & Category & Interval of Mean \\
\hline 4 & Very Good & $3.25 \leq \mathrm{x} \leq 4$ \\
3 & Good & $2.24 \leq \mathrm{x} \leq 3.25$ \\
2 & Poor & $1.74 \leq \mathrm{x} \leq 2.24$ \\
1 & Very Poor & $1 \leq \mathrm{x} \leq 1.74$ \\
\hline
\end{tabular}

\section{FINDINGS AND DISCUSSION}

\section{Findings}

In the weblog development, the needs analysis was the first stage that was conducted to obtain information related to the target and learning needs of eleventh-grade students of senior high school. To obtain the maximum information, the researcher did the needs analysis by engaging the English teacher as well. The needs analysis was done by distributing questionnaires for students and interviewing the English teacher. In terms of target needs, the questionnaires and the interview were divided into three components, they are: necessities lacks and wants. The learning needs are divided into input, procedures, setting, students' role, and the teachers' role. The researcher asked questions about those aspects to know what the students need to be able to learn English. The result of the questionnaires was analyzed and interpreted to explain the result.

After conducting a need analysis, the researcher composed the course grid of the developed materials. The course grid was created based on the result of need analysis and the basic competencies of the School-based curriculum (KTSP). The course grid was elaborated based on the points stated in the School-based curriculum, particularly, basic competences number $6.1,6.2,12.1$, and 12.2. Furthermore, the activities in the materials were also arranged by using a text-based approach. In these materials, there were five types of text. they were a report, narrative, spoof, analytical exposition, and hortatory exposition. Moreover, the narrative text was divided into two units. Hence, in each unit, there was also one genre which was presented to the learners.

In the development of weblog, the researcher compared the available weblog applications such as Blogger, Wordpress, and NEO Learning Management System. Some points to be compared were about the update support from the application developer, availability of plugin and the cost. The researcher selected the NEO Learning Management System as the application 
in developing weblog. All the features offered by this application are very valuable for this research. Additionally, this application provides 14 days of premium features for a new administrator. After developing the weblog by using NEO-LMS, the weblog was uploaded on cloud storage hence all the users could visit the weblog everywhere. The weblog address is http://writing.neolms.com.

The validation toward the media of this weblog product was conducted by using seventeen questions categorized into four groups: display, navigation, feedback, and flexibility. Those aspects were validated by Dra. Pangesti Wiedarti, M.Appl. Ling., PhD. The validation was held in December 2018. The result of expert judgment was used to revise and rearrange weblog becomes better online media.

\section{Discussions}

The kind of media used in the teaching and learning process in the eleventh grade of SMAN 1 Piyungan. Based on the interview of an English teacher at SMAN 1 Piyungan, the teacher usually makes use the Microsoft PowerPoint as the media in teaching and learning English. With the development of technology, the English teacher strongly needs more variety of media to get closer to Information Communication and Technology. The teacher believes that teaching aids certainly amplify her effortful presentation more into influencing instructions, increasing interest, saving the time, and holding the attention. This statement is in accordance with Thomas's (2014) explanation. The use of a variety of teaching aids has successfully transformed most classrooms from traditional setup into participatory learning centers facilitating productive learning.

The weblog as online media that has been developed by the researcher brings two important features needed by the teacher and students. Those are the capability of creating autonomous learning and giving direct feedback on students' activities. The media as Webbased Computer Assisted Language Learning have some advantages for teaching and learning as stated by Falloon (1999), similarly Lasagabaster \& Manuel Sierra (2003). They specified teacher who makes use of online media in teaching and learning process has an opportunity for creating autonomous learning. Besides offering learner autonomy, they are also offering feedback, non-traditional feature, and capability of repetitions.

Table 2. The result of media expert Judgment

\begin{tabular}{lc}
\hline \multicolumn{1}{c}{ Categories } & Score \\
\hline Display appropriateness & 3.71 \\
\hline
\end{tabular}




\begin{tabular}{ll}
\hline Navigation icon appropriateness & 3.75 \\
Feedback appropriateness & 4.00 \\
Flexibility & 4.00 \\
\hline \multicolumn{2}{c}{ Total mean } \\
\hline
\end{tabular}

It is found that the total mean on the media appropriateness is 3.82. According to the qualitative data conversion proposed by (Suharto, 2006), it belongs to a "very good" category because its position was within the interval of $3.25 \leq \mathrm{x} \leq 4$. As a result, the weblog is very appropriate to use in the teaching and learning process for grade eleventh students of Senior High school.

Table 3. Try out result

\begin{tabular}{cc}
\hline Students' responses to the content of the product & 3.28 \\
Students' responses to the weblog elements & 3.82 \\
Students' responses to the operational media & 3.35 \\
\hline Total mean & $\mathbf{3 . 4 8}$ \\
\hline
\end{tabular}

Indeed, the advantages of the weblog are intended for enabling learners in improving their skills. The existence of weblog as online media in the classroom nowadays gives a chance to innovate the learning system as stated by Weller, Pegler, \& Mason (2005). If the weblog is elaborated more intensively, its advantages can help the teacher in teaching language, include English. The presence of different online media in the classroom give more insights for English teacher in teaching writing. Moreover, Warschauer (1997) highlights possibilities to teach new types of writing through the combination of the internet and electronic devices, especially computers.

Another significant point to discuss is that the gap between teachers and students in understanding and using the latest technology. The English teachers and students could come from a different era. Especially for the teachers, they should be able to be an instructor of the media. The teachers need to clarify, assist, and aid in technical problems that may occur. Additionally, schools need to provide additional training for an English teacher to get more knowledge of other applications or programs linked to the media. However, based on Terrill's explanation (2000), those additional training may have additional costs and time.

Finally, based on the evaluation of the product, the students agree that the developed weblog is an effective medium in learning writing. It was shown in table 3 that the weblog is suitable for their needs, can improve their ability and motivation to write. Moreover, these are supported by Fraser (1994) explanation. Fraser characterized effectiveness as a proportion of 
the match between expressed objectives and their accomplishment. It is constantly conceivable to accomplish 'easy'.

The product also matches with seven of nine criteria of effective media proposed by Hubbard (1983). First, the product was developed without any rent of web-hosting. It means the school is not required to spend more money on using the media. Second, the availability of electricity in school becomes one of the supporting facilities. The computer and Wi-Fi router need electricity to use. Third, the weblog is compatible with the class size. It could cover 400 students' maximum. Fourth, the material able to edit. Then, the effect caused by the weblog. The students become more autonomous in learning writing. Next, the organizer features help the weblog meet the conciseness of the media. And the last is usability. The web-based application enables students learning writing everywhere and anytime by using a desktop browser or mobile applications. The last two criteria that unmatched with Hubbard's criteria are about preparation time and complexity. The English teacher needs more time to understand the web-based applications especially the complexity of the administrator features before using them in the teaching and learning process. However, based on the explanation before that, the developed product can be used in teaching English text since it has good media appropriateness with eleventh-grade students of Senior High school.

\section{CONCLUSION}

In the development of technology, it should help teachers in the classroom setting to assist students' learning. Teachers nowadays are challenged to choose the best technology tool without losing the essence goal for students learning. The influence of the internet makes the development of the media wider day by day. An online medium makes teaching and learning process more attractive. Teaching and learning by using online media is one way to get closer to Information Communication and Technology (ICT).

Weblog as an online product has a certain characteristic to overcome students' reluctance and teacher's weaknesses in writing class. In the development of teaching media, the English teachers realize the importance of online media in the process of teaching and learning. In developing the online media, the English teacher should have the basic ability to operate a weblog and spare more time to design the medium.

The weblog as online media developed by the researcher has been validated by experts and teacher. The result of the test indicates the weblog belongs to a very good category. It is also supported by the students' responses that the weblog belongs to a very good category. To 
sum up, the product is appropriate and recommended to be used in writing class since the result of evaluation from experts and the teacher followed by students' responses on the product and their implementation on the tryout showed a positive response.

To achieve the goal of teaching writing, some points should be taken into account by the teachers when using genre-based materials combined with online media. First, the online class is not created to replace the traditional classroom. The teacher should play the roles of the instructor. Hence, the teacher facilitating, guiding and controlling the students' activities as well as clarifying, assisting, and aiding in technical problems that may occur.

For those who are going to develop other learning media, there are some aspects to be considered. First, the content is based on the students' needs, the curriculum, as well as designed sequentially. Then, the materials should consider the students' language level and relevance. Furthermore, the developed media should promote students' autonomy, give direct feedback and repetitions. The learning activities are also varied. These aspects are important to promote the students' motivation in learning English.

\section{BIBLIOGRAPHY}

Başöz, T., \& Çubukçu, F. (2014). Pre-service EFL Teacher's Attitudes towards Computer Assisted Language Learning (CALL). Procedia - Social and Behavioral Sciences, 116, 531-535. https://doi.org/https://doi.org/10.1016/j.sbspro.2014.01.253

Beatty, K. (2013). Teaching and researching computer-assisted language learning, Second edition. Teaching and Researching Computer-Assisted Language Learning, Second edition. https://doi.org/10.4324/9781315833774

Falloon, G. (1999). Developing exemplary practice: why are some teachers better at it than others. Computers in New Zealand Schools, 11(3), 19-23.

Fraser, M. (1994). Quality in higher education: an international perspective. In D. Green (Ed.), What is Quality in Higher Education (pp. 101-111). Buckingham: Open University press and Society for Research into Higher Education.

Hietanen, L., Ruokonen, I., Ruismäki, H., \& Enbuska, J. (2016). Student Teachers' Guided Autonomous Learning: Challenges and Possibilities in Music Education. Procedia Social and Behavioral Sciences, 217, 257-267. https://doi.org/https://doi.org/10.1016/j.sbspro.2016.02.080

Hubbard, P. (1983). Language Teaching Approaches, The evaluation of CALL Software and Design Implications. Lincolnwood, IL: National Textbook Company.

Karimkhanlooei, G., \& Seifiniya, H. (2015). Teaching Alphabet, Reading and Writing for Kids between 3-6 Years Old as a Second Language. Procedia - Social and Behavioral Sciences, 192, 769-777. https://doi.org/https://doi.org/10.1016/j.sbspro.2015.06.090

Kim, M., \& Crossley, S. A. (2018). Modeling second language writing quality: A structural equation investigation of lexical, syntactic, and cohesive features in source-based and independent writing. Assessing Writing, 37, 39-56. https://doi.org/https://doi.org/10.1016/j.asw.2018.03.002 
Kramer, Ij. M., \& Kusurkar, R. A. (2017). Science-writing in the blogosphere as a tool to promote autonomous motivation in education. The Internet and Higher Education, 35, 48-62. https://doi.org/https://doi.org/10.1016/j.iheduc.2017.08.001

Lasagabaster, D., \& Manuel Sierra, J. (2003). Students' evaluation of CALL software programs. Educational Media International, 40(3-4), 293-304. https://doi.org/10.1080/0952398032000113211

Lee, M.-K. (2015). Peer feedback in second language writing: Investigating junior secondary students' perspectives on inter-feedback and intra-feedback. System, 55, 1-10. https://doi.org/https://doi.org/10.1016/j.system.2015.08.003

Leiker, A. M., Bruzi, A. T., Miller, M. W., Nelson, M., Wegman, R., \& Lohse, K. R. (2016). The effects of autonomous difficulty selection on engagement, motivation, and learning in a motion-controlled video game task. Human Movement Science, 49, 326-335. https://doi.org/https://doi.org/10.1016/j.humov.2016.08.005

Pirasteh, P. (2014). The Effectiveness of Computer-assisted Language Learning (CALL) on Learning Grammar by Iranian EFL Learners. Procedia - Social and Behavioral Sciences, 98, 1422-1427. https://doi.org/https://doi.org/10.1016/j.sbspro.2014.03.561

Rafiee, S. J., \& Purfallah, S. A. (2014). Perceptions of Junior High school Teachers toward Computer Assisted Language Learning (CALL) within the Context of Azarbayjan Provinces. Procedia - Social and Behavioral Sciences, 98, 1445-1453. https://doi.org/https://doi.org/10.1016/j.sbspro.2014.03.564

Smaldino, S., Lowther, D., \& Russell, J. (2005). The ASSURE Model: Creating the Learning Experience. Instructional Technology and Media for Learning.

Stickler, U., \& Shi, L. (2016). TELL us about CALL: An introduction to the Virtual Special Issue (VSI) on the development of technology enhanced and computer assisted language learning published in the System Journal. System, 56, 119-126. https://doi.org/https://doi.org/10.1016/j.system.2015.12.004

Su, C., Tseng, C., Jang, J.-S. R., \& Visceglia, T. (2018). A hierarchical linguistic informationbased model of English prosody: L2 data analysis and implications for computer-assisted language learning. Computer Speech \& Language, 51, 44-67. https://doi.org/https://doi.org/10.1016/j.csl.2018.03.001

Suharto, G. (2006). Pengukuran penilaian hasil belajar bahasa inggris. Yogyakarta: P3B UNY.

Terrill, L. (2000). Benefits and Challenges in Using Computers and the Internet with Adult English Learners. National Center for ESL Literacy Education (NCLE).

Thomas, M. (2014). Effective Teaching: a Measure of Excellence (5th editio). New Delhi; S. Chand \& Company Ltd.

Warschauer, M. (1997). Computer-Mediated Collaborative Learning: Theory and Practice. The Modern Language Journal. https://doi.org/10.2307/328890

Weller, M., Pegler, C., \& Mason, R. (2005). Use of innovative technologies on an e-learning course. Internet and Higher Education. https://doi.org/10.1016/j.iheduc.2004.10.001

Zaini, A., \& Mazdayasna, G. (2014). The Effect of Computer Assisted Language Learning on the Development of EFL Learners' Writing Skills. Procedia - Social and Behavioral Sciences, 98, 1975-1982. https://doi.org/https://doi.org/10.1016/j.sbspro.2014.03.631 